\title{
Association of spirochetal infection with Morgellons disease
}

\section{[version 1; peer review: 2 approved]}

\author{
Marianne J Middelveen ${ }^{1}$, Divya Burugu², Akhila Poruri², Jennie Burke³, \\ Peter J Mayne1, Eva Sapi², Douglas G Kahn4, Raphael B Stricker ${ }^{1}$ \\ ${ }^{1}$ International Lyme and Associated Diseases Society, Bethesda, MD, 20827, USA \\ ${ }^{2}$ Department of Biology and Environmental Science, University of New Haven, West Haven, CT, 06516, USA \\ ${ }^{3}$ Australian Biologics, Sydney, 2000, Australia \\ ${ }^{4}$ Department of Pathology, Olive View-UCLA Medical Center, Sylmar, CA, 91342, USA
}

\author{
V1 First published: 28 Jan 2013, 2:25 \\ https://doi.org/10.12688/f1000research.2-25.v1 \\ Latest published: 28 Jan 2013, 2:25 \\ https://doi.org/10.12688/f1000research.2-25.v1
}

\section{Open Peer Review}

\begin{tabular}{lccc} 
Approval Status & 1 & 2 & 3 \\
\hline version 1 & & & \\
28 Jan 2013 & view & & view
\end{tabular}

1. Judith Miklossy, Alzheimer Prevention

Foundation, Martigny-Croix, Switzerland

2. Bernhard Zelger, Medical University

Innsbruck, Innsbruck, Austria

3. John English, Queen's Medical Centre, Nottingham University Hospitals NHS Trust, Nottingham, UK

Any reports and responses or comments on the article can be found at the end of the article.

Keywords

Morgellons disease, digital dermatitis, Lyme disease, Borrelia burgdorferi, spirochetes. 
Corresponding author: Raphael B Stricker (rstricker@usmamed.com)

Competing interests: RBS serves without compensation on the medical advisory panel for QMedRx Inc. He has no financial ties to the company. MJM serves without compensation on the scientific advisory panel of the Charles E. Holman Foundation. PJM and RBS serve without compensation on the medical advisory panel of the Charles E. Holman Foundation. DB, AP, JB, ES and DGK have no conflicts to declare.

Grant information: Partial funding for this study was provided by the Charles E. Holman Foundation, Austin, TX. The funders had no role in study design, data collection and analysis, decision to publish, or preparation of the manuscript.

Copyright: ( $) 2013$ Middelveen MJ et al. This is an open access article distributed under the terms of the Creative Commons Attribution License, which permits unrestricted use, distribution, and reproduction in any medium, provided the original work is properly cited.

How to cite this article: Middelveen MJ, Burugu D, Poruri A et al. Association of spirochetal infection with Morgellons disease [version 1; peer review: 2 approved] F1000Research 2013, 2:25 https://doi.org/10.12688/f1000research.2-25.v1

First published: 28 Jan 2013, 2:25 https://doi.org/10.12688/f1000research.2-25.v1 


\section{Introduction}

Morgellons disease (MD) is an evolving skin disease associated with filaments found beneath unbroken skin or projecting from spontaneously-appearing, slowly-healing skin lesions ${ }^{1}$. In addition to dermopathy, patients may also exhibit debilitating musculoskeletal and neurological manifestations resembling the symptoms of Lyme disease ${ }^{1,2}$. Similarities were found between MD and bovine digital dermatitis (BDD), a disease common in dairy herds and characterized by keratin filament formation in skin lesions that frequently occur above the hind feet of cows ${ }^{3,4}$. Chronic BDD lesions demonstrate proliferation of long keratin filaments, and microscopic examination of histological sections from this tissue has revealed the presence of various Treponema spp. among enlarged keratinocytes throughout the stratum spinosum and dermal papillae ${ }^{5-9}$.

The etiology of BDD is considered to be multifactorial with coinvolvement of spirochetes and other bacterial pathogens ${ }^{10-14}$. In the animal disease, repeated detection of spirochetes from lesions and sero-reactivity to Borrelia burgdorferi antigens provides evidence of spirochetal involvement ${ }^{10-14}$. Successful experimental infection with tissue homogenates and pure cultured treponemes has confirmed that spirochetes are primary etiologic agents ${ }^{15,16}$.

Like BDD, MD filaments are produced by epithelial cells and stem from the stratum basale and from the root sheath of hair follicles, thus providing evidence that the filaments are cellular in origin ${ }^{3,4}$. Furthermore, immunohistochemical and histological staining has demonstrated that these filaments have a collagen as well as a keratin component ${ }^{5,17}$. Like cattle with BDD, patients with MD also produce antibodies reactive to Borrelia burgdorferi antigens ${ }^{18}$. Multisystemic symptoms resembling Lyme disease also imply a possible spirochetal etiology for $\mathrm{MD}^{1-3,18,19}$. The frequent clinical diagnosis of Lyme disease and coinfecting tick-borne pathogens in MD patients suggests a multifactorial etiology and possible vectoring by ticks ${ }^{1-3,18,19}$.

In light of the proven spirochetal association with BDD and the possible association with MD, we undertook a histological, electron microscopic and PCR study of MD dermatological tissue samples to investigate the presence of spirochetes in these samples. In addition, bacterial culture was conducted to investigate the possibility of viable spirochetes in MD tissue.

\section{Materials and methods}

Patient selection and dermatological samples

Representative non-biopsy dermatological specimens were collected from four randomly-selected patients who met the key clinical criterion for MD, namely that filaments visible with a hand-held microscope at $60 \mathrm{X}$ magnification must be present under unbroken skin or projecting from spontaneously appearing skin lesions. Patients 1 and 2 are Americans residing in Texas while patients 3 and 4 are Canadians residing in Alberta, Canada (Table 1). Written informed consent for submission of clinical samples and publication of clinical details and clinical images was obtained from each study subject. Patient anonymity and confidentiality were strictly maintained. The study was exempt from Institutional Review Board approval because all testing was performed as part of routine clinical care, and patient anonymity and confidentiality were strictly maintained.

The detailed histopathological findings in these patients were reported previously ${ }^{17}$. All patients were seroreactive to Borrelia burgdorferi antigens (strains B31 and 297, IGeneX Laboratory, Palo Alto, CA) and negative on rapid plasma reagin (RPR) testing (RPR Card Test Kit, BD Diagnostic Systems, Sparks, MD). Patient 1 was on doxycycline therapy for Lyme disease at the time of the study, while patient 2 had previously been treated with doxycycline for Lyme disease but had been off treatment for several years at the time of the study. Patients 3 and 4 were not on antibiotic therapy at the time of the study. None of the study patients had evidence of a delusional disorder, as determined by standard neuropsychiatric testing using the Rorschach, Minnesota Multiphasic Personality Inventory (MMPI), Millon Clinical Multiaxial Inventory (MCMI) and Wechsler Adult Intelligence Scale (WAIS) formats.

The late-stage BDD biopsies used for comparison were kindly provided by Dr. Dorte Döpfer, Faculty of Veterinary Medicine, University of Wisconsin, Madison, WI. Biopsies were taken as part of an intervention study conducted by the University of Wisconsin ${ }^{15}$. The diagnostic criterion for late-stage BDD was the presence of pronounced keratin projections from ulcerative lesions that were at least two centimeters in diameter and located above the heel bulb of the hind feet of cattle. Biopsy samples were stored and shipped in a fixative of $1.5 \%$ glutaraldehyde $1.0 \%$ formaldehyde in Sorensen's Buffer at pH 7.35 (Tousimis Research Corporation, Rockville, MD).

Table 1. Summary of Morgellons disease patient data.

\begin{tabular}{|llllllll|} 
Patient & Age/Sex & Residence & RPR & $\begin{array}{l}\text { Lyme } \\
\text { serology }\end{array}$ & $\begin{array}{l}\text { Delusional } \\
\text { illness }\end{array}$ & Antibiotic therapy & Coinfections \\
\hline 1 & $72 \mathrm{~F}$ & $\begin{array}{l}\text { San Antonio, TX, Negative } \\
\text { USA }\end{array}$ & Positive & None & $\begin{array}{l}\text { Currently taking } \\
\text { doxycycline }\end{array}$ & $\begin{array}{l}\text { Babesiosis and } \\
\text { Bartonellosis }\end{array}$ \\
\hline 2 & $49 \mathrm{~F}$ & $\begin{array}{l}\text { Hughes Springs, } \\
\text { TX, USA }\end{array}$ & Negative & Positive & None & $\begin{array}{l}\text { Previous doxycycline } \\
\text { therapy }\end{array}$ & Ehrlichiosis \\
\hline 3 & $54 \mathrm{~F}$ & $\begin{array}{l}\text { Cardston, AB, } \\
\text { Canada }\end{array}$ & Negative & Positive & None & None & Unknown \\
\hline 4 & $73 \mathrm{~F}$ & $\begin{array}{l}\text { Calgary, AB, } \\
\text { Canada }\end{array}$ & Negative & Positive & None & None & Unknown \\
\hline
\end{tabular}

RPR, rapid plasma reagin test. 
Duplicate samples were used for each of the light and electron microscopic studies described below.

\section{Light microscopy}

The gross morphology of dermatological specimens collected from Patients 1-4 was observed at $8 \mathrm{X}, 40 \mathrm{X}$, and $100 \mathrm{X}$ magnification with illumination superior to the specimen, thus verifying the presence of filaments within and protruding from epithelial tissue. BDD biopsy material was examined at $8 \mathrm{X}$ to observe gross morphological characteristics.

Morgellons samples were formalin-fixed and embedded in paraffin, sectioned, and stained with Warthin-Starry and/or Dieterle silver nitrate-based staining for the light microscopic detection of spirochetes under oil immersion at 1000X magnification. Warthin-Starry staining and Dieterle staining were performed by Interscope Pathology Medical Group, Canoga Park, CA, and McClain Laboratories LLC, Smithtown, NY, respectively.

BDD biopsies were formalin-fixed and embedded in paraffin, sectioned, and stained for the detection of spirochetes by WarthinFaulkner silver nitrate-based staining at Prairie Diagnostics, University of Saskatchewan, Saskatoon, Saskatchewan.

Formalin-fixed paraffin-embedded MD sections were processed for immunofluorescent anti-Borrelia staining and imaging as previously described ${ }^{20}$ at the University of New Haven, West Haven, CT, by the following protocol: fixed specimens were pre-incubated with $10 \%$ normal goat serum (Thermo Fisher Scientific, Waltham, MA) in PBS containing $0.5 \%$ bovine serum albumin (BSA) (SigmaAldrich, St. Louis, MO) for 30 minutes to block non-specific binding of the secondary antibody. The slides were washed with PBS containing $0.5 \%$ BSA and then incubated for 1 hour with fluorescein isothiocyanate (FITC)-labelled Borrelia-specific polyclonal antibody (Thermo Fisher Scientific, \#73005) at a 1:50 dilution in PBS containing $1 \%$ BSA pH 7.4. The slides were washed and then counterstained with 4', 6-diamidino-2-phenylindole (DAPI) for 10 minutes. In negative control samples, anti-specifically targeted antibody was replaced with normal rabbit IgG (Vector Laboratories, Burlingame, CA, \#I-1000). Mounted slides were imaged using fluorescent microscopy.

\section{Electron microscopy}

Morgellons and BDD samples were fixed in buffered $2.5 \%$ glutaraldehyde. Scanning electron microscopy (SEM) and transmission electron microscopy (TEM) were performed by the Electron Microscopy Facility, Department of Materials Science and Engineering, Clemson University, Anderson, SC, according to the protocols below:

SEM. Glutaraldehyde-fixed samples for SEM were washed in buffer and dehydrated in a graded series of ethanol concentrations. Samples were then immersed in hexamethyldisilazane (Electron Microscopy Sciences, Hatfield, PA) for 5-15 minutes and air dried at room temperature. Dried samples were mounted on A-1 mounts. Samples were not coated but placed into a Hitachi TM3000 microscope and imaged in the variable pressure mode.
TEM. Glutaraldehyde-fixed samples were washed in buffer, followed by dehydration in a graded series of ethanol concentrations. Samples were then immersed in a 50:50 mixture of LR White ${ }^{\mathrm{TM}}$ embedding resin and $100 \%$ ethanol for 30 minutes, followed by pure LR White ${ }^{\mathrm{TM}}$ resin until samples settled on the bottom of the vial. The resin-immersed samples were then placed into pure resin in beam capsules and put into a $60^{\circ} \mathrm{C}$ oven overnight for polymerization. Sections were cut on an Ultracut E microtome to produce sections 60-90 nm thick, placed onto copper grids and stained in uranyl acetate for 20 minutes. Images were taken on a Hitachi 7600 microscope.

\section{PCR}

Morgellons calluses from patients $1-4$ were forwarded to Australian Biologics (Sydney, Australia) for B. burgdorferi detection by PCR using the $\mathrm{Eco}^{\mathrm{TM}}$ Real-Time PCR system with software version 3.0.16.0. DNA was extracted from the tissue samples using the QIAamp DNA Mini Kit (QIAGEN). The four samples were analyzed in duplicate with positive and negative controls using primers AB-B1 for the Borrelia 16S rRNA gene target, as previously described $^{21}$. The thermal profile for all analyses involved incubation for 2 mins at $50^{\circ} \mathrm{C}$, polymerase activation for $10 \mathrm{mins}$ at $95^{\circ} \mathrm{C}$ then PCR cycling for 40 cycles of 10 secs at $95^{\circ} \mathrm{C}$ dropping to $60^{\circ} \mathrm{C}$ sustained for 45 secs.

The magnitude of the PCR signal generated $(\Delta \mathrm{R})$ for each sample was interpreted as positive or negative compared to positive and negative controls.

\section{Borrelia spp. culture}

Borrelial culture was performed as described previously ${ }^{22}$. B. burgdorferi was cultured in Barbour-Stoner-Kelly H (BSK-H) complete medium, with 6\% rabbit serum (Sigma Aldrich, \#B8291) and the following antibiotics: phosphomycin $(0.02 \mathrm{mg} / \mathrm{l})$, rifampicin $(0.05 \mathrm{mg} / \mathrm{l})$, and amphotericin B $(2.5 \mu \mathrm{g} / \mathrm{l})$ (Sigma-Aldrich) and incubated at $32^{\circ} \mathrm{C}$ with $5 \% \mathrm{CO}_{2}$. Cultured spirochetes were observed by dark-field microscopy and/or heat-fixed and stained with crystal violet (Dalynn Biologicals, Calgary, AB) under oil immersion at 1000X. For the immunofluorescence studies, cultured spirochetes $\left(1 \times 10^{7}\right.$ individual spirochete cells) were centrifuged at $8,000 \times \mathrm{g}$ for 10 minutes at room temperature, washed once with $\mathrm{PBS} \mathrm{pH}$ 7.4 , and then centrifuged again at $8,000 \times \mathrm{g}$ for 10 minutes at room temperature. The pellet was resuspended in $100 \mu \mathrm{l}$ of PBS pH 7.4, and then spread on microscope slides (SuperFrost+, Thermo Fisher Scientific). Spirochetes were fixed by incubating the slides in cold acetone for 10 minutes at $-20^{\circ} \mathrm{C}$. Slides were then washed twice with $\mathrm{PBS} \mathrm{pH} 7.4$ at room temperature, and.immunofluorescent staining with polyclonal anti-Borrelia antibodies was performed as described above.

\section{Results}

Gross microscopic observations

Calluses from the four MD patients demonstrated white, red and blue filaments, alone or in any color combination, each 10 to $40 \mu \mathrm{m}$ in diameter, embedded in or projecting from epithelial tissue (Figure 1A). BDD biopsies demonstrated pronounced, unusual keratin filament production typical of late-stage proliferative infection (Figure 1B). 


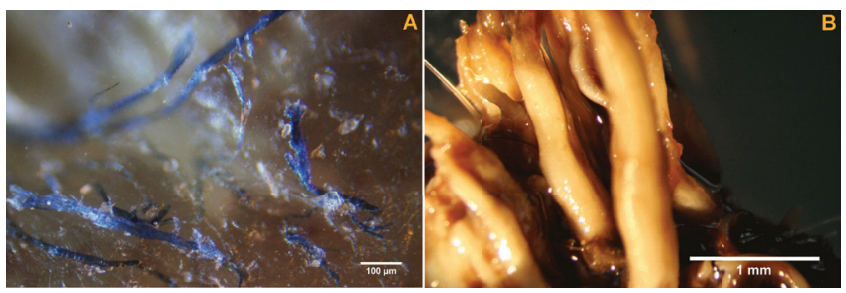

Figure 1. A) Morgellons disease filaments embedded in and projecting from epithelial tissue, 100X magnification. B) Proliferative bovine digital dermatitis (BDD) keratin filaments, 8x magnification.

A summary of the following histological, culture, electron microscopic and PCR results is shown in Table 2.
Light microscopy

Silver nitrate-based staining. Staining of dermatological tissue from patients 1-4 revealed visible black-stained spirochetes among keratinocytes and inflammatory cells (Figure 2A). These spiral or curved structures ranged from $0.1 \mu \mathrm{m}$ to $0.5 \mu \mathrm{m}$ in diameter and up to $30 \mu \mathrm{m}$ long, and they were present mostly in the interior areas of the sections and not along the peripheral edge.

Staining of BDD dermatological tissue revealed visible blackstained spirochetes among enlarged keratinocytes (Figure 2B). Spirochetes were approximately $0.1 \mu \mathrm{m}$ to $0.2 \mu \mathrm{m}$ in diameter and approximately $10 \mu \mathrm{m}$ to $15 \mu \mathrm{m}$ in length, and they varied in morphology from visibly spiral-shaped to straight or wavy in appearence.

\section{Table 2. Summary of laboratory findings in Morgellons disease patients.}

\begin{tabular}{|llllll|} 
Patient & $\begin{array}{l}\text { Silver nitrate } \\
\text { staining }\end{array}$ & Culture & IFA staining & SEM/TEM & PCR \\
\hline 1 & $\begin{array}{l}\text { Spirochetes } \\
\text { detected }\end{array}$ & Not performed & $\begin{array}{l}\text { Positive, histological } \\
\text { sections }\end{array}$ & $\begin{array}{l}\text { Spirochetes observed, } \\
\text { TEM }\end{array}$ & $\begin{array}{l}\text { Weak } \\
\text { positive }\end{array}$ \\
\hline 2 & $\begin{array}{l}\text { Spirochetes } \\
\text { detected }\end{array}$ & Not performed & $\begin{array}{l}\text { Positive, histological } \\
\text { sections }\end{array}$ & $\begin{array}{l}\text { Spirochetes observed, } \\
\text { both SEM and TEM }\end{array}$ & Positive \\
\hline 3 & $\begin{array}{l}\text { Spirochetes } \\
\text { detected }\end{array}$ & $\begin{array}{l}\text { Positive, motile spirochetes } \\
\text { detected, confirmed by IFA } \\
\text { staining }\end{array}$ & $\begin{array}{l}\text { Positive, both histological } \\
\text { sections and cultured } \\
\text { spirochetes }\end{array}$ & Not performed & Positive \\
\hline 4 & $\begin{array}{l}\text { Spirochetes } \\
\text { detected }\end{array}$ & $\begin{array}{l}\text { Positive, motile spirochetes } \\
\text { detected }\end{array}$ & $\begin{array}{l}\text { Positive, histological } \\
\text { sections }\end{array}$ & Not performed & Negative \\
\hline
\end{tabular}

IFA, immunofluorescence assay; SEM, scanning electron microscopy; TEM, transmission electron microscopy; PCR, polymerase chain reaction.
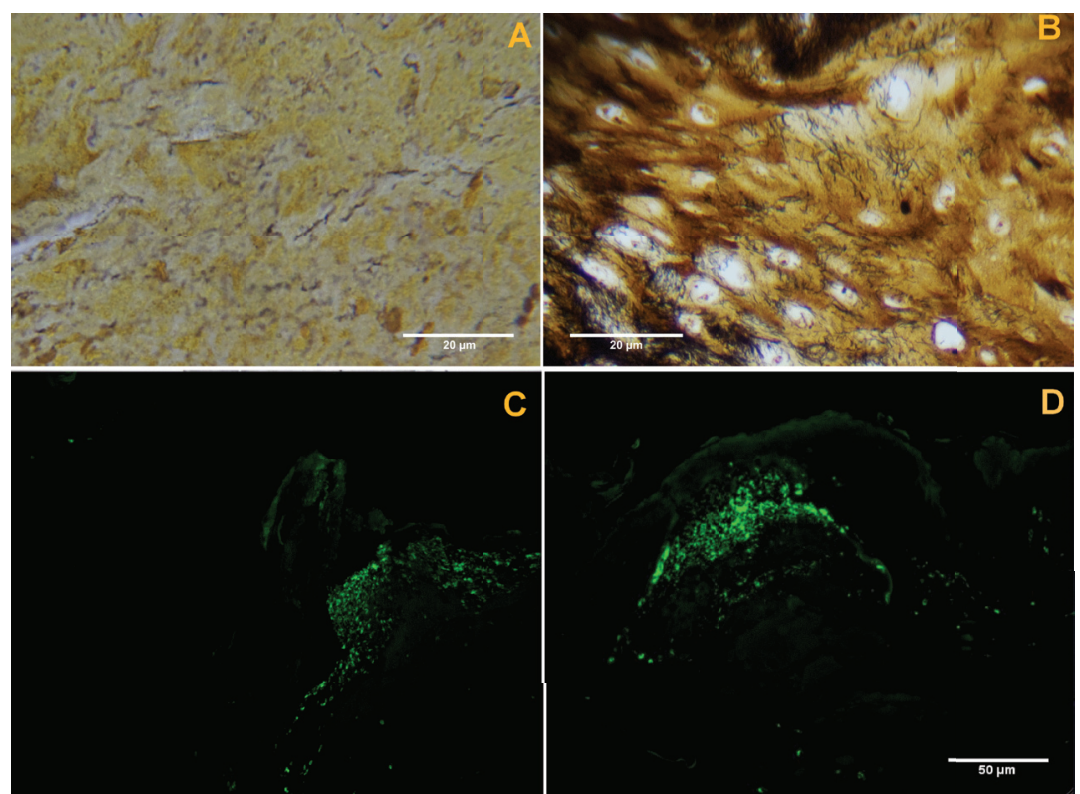

Figure 2. A) Black-stained spirochetes in representative tissue sample from patient 2. Dieterle stain, 1000X oil immersion. B) Black-stained spirochetes in bovine digital dermatitis (BDD) tissue sample, Warthin-Faulkner stain, 1000X oil immersion. C) Distinct patches of anti-Borrelia fluorescence in histological section of callus from patient 1, 400X magnification. D) Distinct patches of anti-Borrelia fluorescence in histological section of callus from patient 2, 400X magnification. 
Immunofluorescent anti-Borrelia staining. Immunofluorescent anti-Borrelia staining of fixed Treponema denticola spirochetes was performed as a negative control and immunofluorescence was not observed for these specimens (data not shown). Histological sections of dermatological material from patients 1-4 all demonstrated distinct patches of immunofluorescence at a magnification of 400X (Figures 2C and 2D). Patches of fluorescence appeared to occur most often in areas of sections corresponding to fibroblasts. Cultured spirochetes from patient 3 also demonstrated positive immunofluorescent staining with anti-Borrelia antibodies (see below and Figure 5C).

\section{SEM and TEM}

SEM revealed high-resolution surface imaging of a spirochete lying beneath a layer of dermatological tissue of a Morgellons callus and images consistent with morphological forms of Borrelia spp. (Figures 3A and 3B). TEM imaging of both Morgellons calluses and BDD biopsies revealed spirochetes in cross-section (Figures 3C and 3D).

\section{PCR}

Real-time PCR analysis was positive for Borrelial DNA in tissue samples from MD patients 1-3 and negative in the sample from Patient 4. Samples from Patients 2 and 3 were clear positives and the sample from Patient 1 was a weak positive. The PCR profiles are shown in Figure 4.

\section{Borrelia spp. culture}

Motile spirochetes ranging from approximately $0.1 \mu \mathrm{m}$ to $0.5 \mu \mathrm{m}$ in diameter and up to $30 \mu \mathrm{m}$ long were visible in cultures inoculated with dermatological tissue from both patients 3 and 4 (Figures 5A and 5B). Cultured spirochetes from patient 3 were identified as Borrelia by immunofluorescent staining with FITClabelled polyclonal antibodies at 1000X magnification (Figure 5C). The culture obtained from the inoculum from patient 4 was lost due to contamination and generic identification was not obtained.

\section{Discussion}

The presence of spirochetes in MD dermatological specimens demonstrates that Morgellons lesions are associated with spirochetal infection. Unlike Treponema pallidum spirochetes, which are seldom detected in secondary and tertiary syphilitic skin lesions ${ }^{23-25}$, spirochetes were readily detectable in dermatological tissue from four MD patients using a combination of immunohistochemical, electron microscopic and PCR techniques. Motile spirochetes were also observed in cultures inoculated with MD dermatological tissue, thus indicating that our specimens contained viable organisms. These findings are similar to the observation of significant spirochetal loads in lesions of cattle with BDD, suggesting that spirochetes could be associated with unusual filament production in both bovines and humans. Although Ekbom reported that syphilitic infection was associated with feelings of infestation ${ }^{26}$, to our knowledge dermal fibers have not been reported in patients with syphilis.
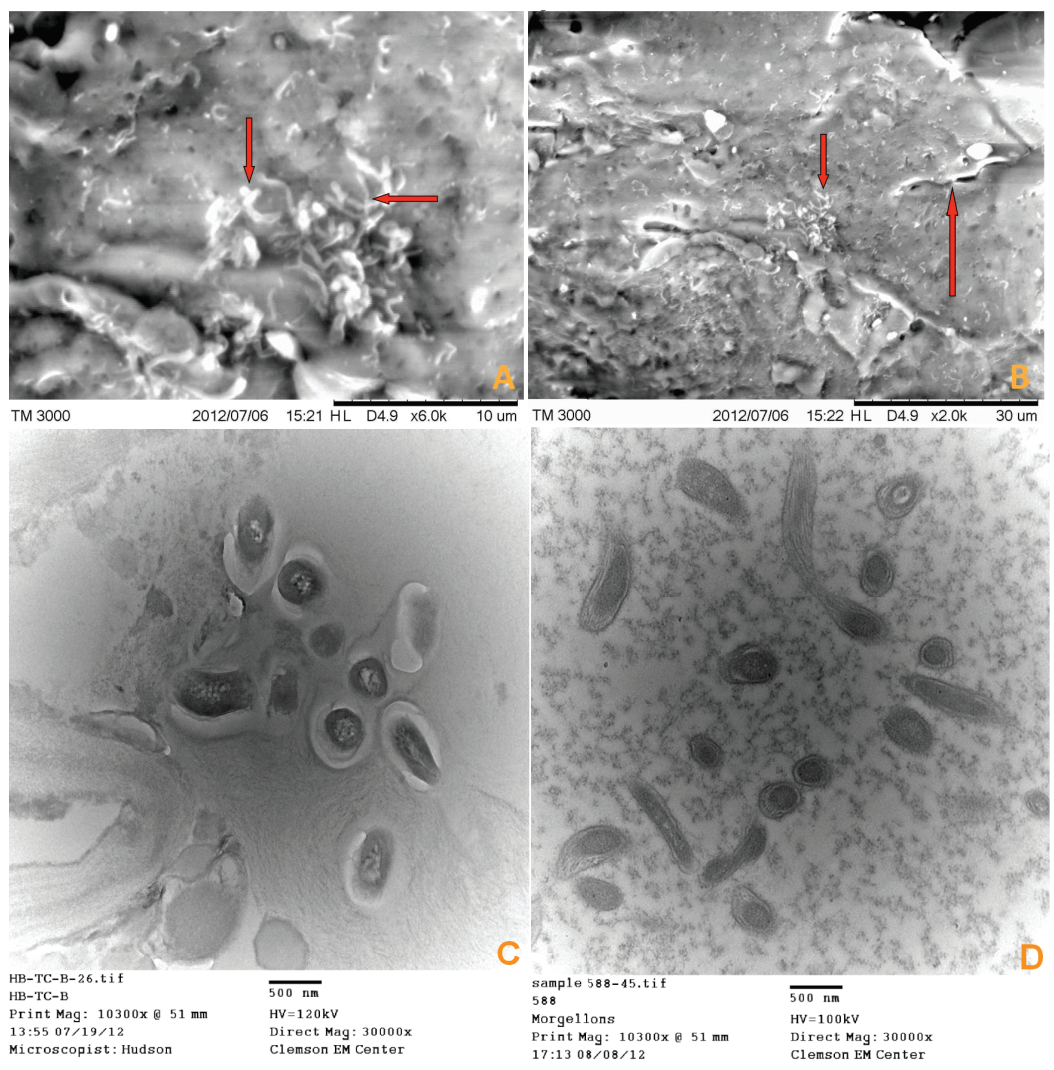

Figure 3. A) SEM from patient 2 tissue sample showing spirochete images that are consistent with morphological forms of Borrelia (arrows). B) SEM from patient 2 tissue sample showing single spirochete, upper middle right (long arrow) and morphological forms consistent with Borrelia, center (short arrow). C) TEM from patient 1 tissue sample showing sectioned spirochetes. D) TEM from BDD tissue sample showing sectioned spirochetes. 


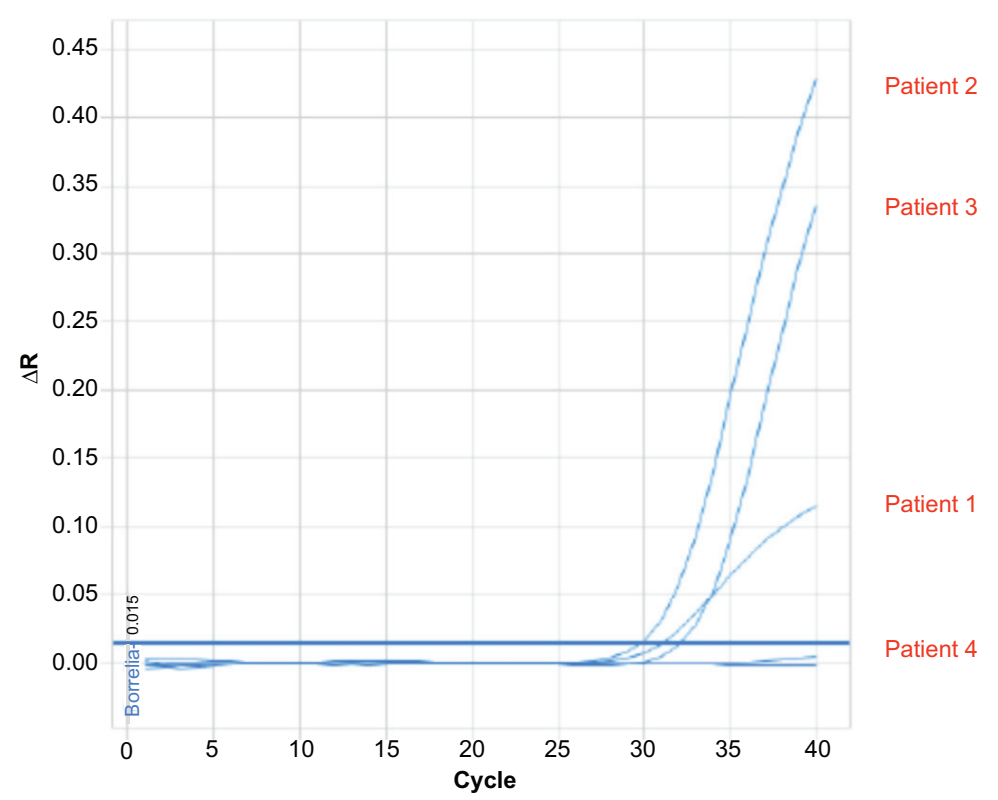

Figure 4. Results of polymerase chain reaction (PCR) amplification in tissue samples from patients 1-4. See text for PCR protocol. Samples from patients 2 and 3 were strongly positive, while the sample from patient 1 was weakly positive. The sample from patient 4 was negative.
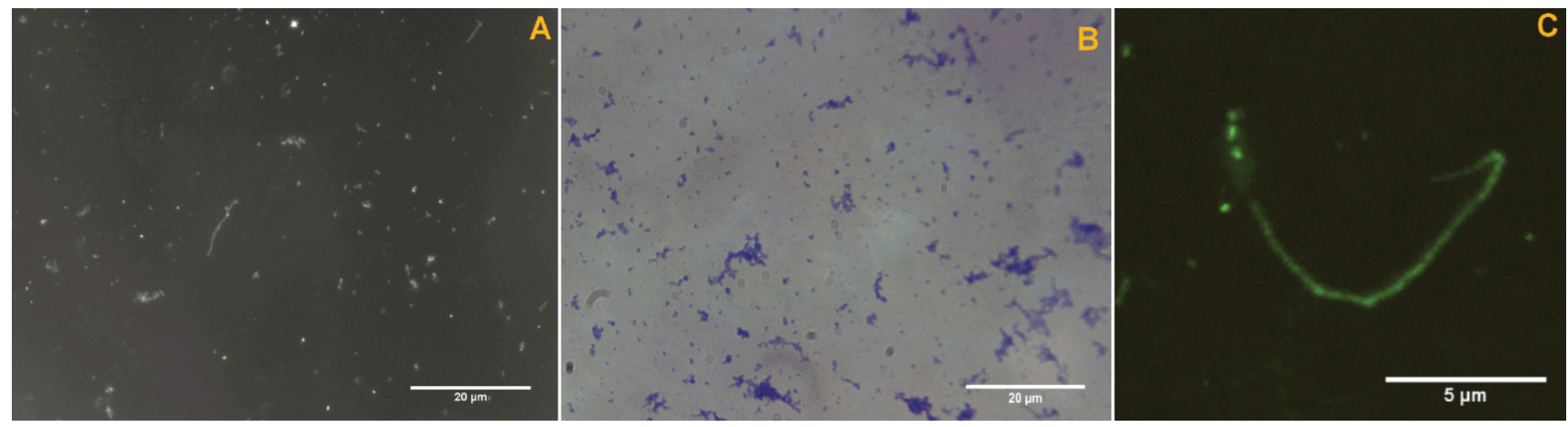

Figure 5. A) Cultured spirochetes from patient 3 tissue samples, 1000X darkfield microscopy, oil immersion. B) Cultured spirochetes in clumps from patient 4 tissue sample, heat fixed and stained with crystal violet, 1000X oil immersion. C) Borrelial spirochetes demonstrating fluorescence from tissue culture of patient 3, 1000X oil immersion, enlarged and cropped.

Unlike BDD, which is associated with a variety of treponemal spirochetes ${ }^{15,16}$, the MD dermatological tissue in this study contained spirochetes that were identified as Borrelia by immunofluorescent staining with anti-Borrelia antibodies. Furthermore the MD spirochetes were specifically classified by targeted PCR as Borrelia burgdorferi. Given the fact that all four MD patients in this study were seroreactive to Borrelia burgdorferi antigens, some of which are thought to be species-specific, and were RPR negative, we speculate that the Morgellons phenomenon observed in our group of study patients is a manifestation of Lyme disease. At present it is not understood if MD filaments are associated exclusively with Borrelia burgdorferi sensu stricto, perhaps a particular genotype, or with a Borrelia species more appropriately placed in the Borrelia burgdorferi sensu lato complex. As our study sample was small, we cannot ascertain at this stage whether Morgellons filaments are associated with spirochetes belonging to other genera as well as Borrelia.

The etiology of MD appears to be multifactorial, and at this stage secondary etiologic factors are not well understood. MD is most often reported in middle-aged Caucasian females. It is a disease reported mostly in the Northern Hemisphere, and it is often associated with known tick exposure, a Lyme disease diagnosis, and serological evidence of coinfecting tick-borne agents s, $^{1,18,19}$. Two of our study patients had laboratory-confirmed tick-borne coinfections (see Table 1), and these coinfections may contribute to the pathology of this disease.

The filaments seen in MD are composed of keratin and collagen derived from keratinocytes and fibroblasts, respectively ${ }^{4,17}$. We 
hypothesize that spirochetes associated with MD trigger the production of unusual collagen and keratin filaments. In our study, spirochetes were detected in Morgellons dermatological tissue from both Patient 1, who was currently taking antibiotics, and from Patient 2, who had been on antibiotic therapy in the past but was not on treatment at the time that samples were obtained. $B$. burgdorferi has been reported to invade human fibroblasts, and viable B. burgdoferi spirochetes have been isolated from lysates of fibroblast monolayers, even after antibiotic therapy ${ }^{27}$. Our findings suggest that Borrelia spirochetes may be capable of sequestering within keratinocytes and fibroblasts, causing both persistent infection that is refractory to antibiotic therapy and aberrant fiber production by these infected cells in MD patients.

Despite contrary evidence, some medical professionals have attributed MD to delusions of parasitosis or delusional infestation. MD is thought to result from psychiatric illness and is diagnosed on the basis of patient belief in infestation by parasites, or the presence of inanimate objects such as fibers that are thought to be deliberately self-implanted ${ }^{28-32}$. As stated above, spirochetal infection associated with itching and crawling sensations and feelings of infestation dates as far back as 1945 in Ekbom's original description of delusions of parasitosis ${ }^{26}$, and many of the patients in that study were diagnosed with syphilis. This clinical observation provides valuable insight into MD.

The insistence that MD is delusional has prevented the establishment of universally accepted, objective diagnostic criteria for this disease. Consequently, some studies have included diverse groups of research subjects, including patients who may not actually have had $\mathrm{MD}^{30-32}$. In the present study, the key diagnostic criterion is that filaments visible with a hand-held microscope at 60X magnification must be present under unbroken skin or projecting from spontaneously-appearing skin lesions ${ }^{1,2}$. This important clinical feature forms the basis for an accurate MD diagnosis.

Although a study from the Centers for Disease Control and Prevention $(\mathrm{CDC})$ found no evidence that pathogens play a role in MD, the search for spirochetal pathogens in that study was confined to Warthin-Starry staining on limited tissue samples and commercial serological testing for Borrelia burgdorferi ${ }^{31}$. Tissue staining in that study was performed on samples from patients who reportedly did not have confirmed clinical evidence of $\mathrm{MD}^{32}$, and serological testing was interpreted in accordance with Lyme surveillance criteria that are inappropriate for clinical diagnosis ${ }^{33}$. Thus the findings in the CDC study were influenced by failure to examine the appropriate group of patients and by the clinical insensitivity of surveillance testing for tickborne disease ${ }^{32,33}$. These limitations leave open the possibility that a spirochetal association with MD could have been missed in the CDC study.

Controversy surrounding MD has been detrimental to those afflicted with this illness. It has stifled scientific research and has prevented appropriate treatment and control strategies from being investigated and implemented. In some cases it has resulted in treatment with ineffective and potentially harmful antipsychotic drugs ${ }^{28-32}$. Some patients have been stigmatized by a diagnosis of mental illness that resulted in social isolation, loss of employment, loss of custody of children, and a high rate of suicide (Casey C. 2012. Personal communication. http://www.thecehf.org/). Further MD research is urgently needed to delineate the possible infectious etiology of the disease and to assure that patients can be appropriately diagnosed and treated in the future.

\section{Conclusions}

This report demonstrates the presence of Borrelia spirochetes in dermatological samples collected from four MD patients who were seroreactive to Borrelia burgdorferi antigens. The findings suggest that MD has a spirochetal etiology and raises the possibility that this emerging dermopathy may be a manifestation of Lyme disease in a subgroup of tickborne disease patients. The demonstration of an infectious agent associated with MD contradicts the belief that patients with this disease suffer from a factitious or delusional illness. Although our sample size was small, our study indicates that, at least in some patients, MD appears to be an important emerging infectious disease. Further research is needed to assure the correct diagnosis and define the optimal treatment for this spirochetal infection so that MD patients are not stigmatized with a diagnosis of mental illness.

\section{Author contributions}

MJM performed the light microscopic studies and spirochete cultures, coordinated the electron microscopic studies and wrote the original manuscript. DB, AP and ES performed the IFA studies. JB and PJM performed the PCR studies. DGK performed the immunohistochemical studies. RBS coordinated all studies, rewrote the manuscript and edited it for publication. All authors approved the manuscript for publication.

\section{Competing interests}

RBS serves without compensation on the medical advisory panel for QMedRx Inc. He has no financial ties to the company. MJM serves without compensation on the scientific advisory panel of the Charles E. Holman Foundation. PJM and RBS serve without compensation on the medical advisory panel of the Charles E. Holman Foundation. DB, AP, JB, ES and DGK have no conflicts to declare.

\section{Grant information}

Partial funding for this study was provided by the Charles E. Holman Foundation.

The funders had no role in study design, data collection and analysis, decision to publish, or preparation of the manuscript.

\section{Acknowledgments}

The authors thank Drs. Stewart Adams, Gordon Atkins, Robert Bransfield, Douglas Demetrick, Dorte Dopfer, JoAnn Hudson, Alan MacDonald, Elizabeth Rasmussen, Virginia Savely, Matthew Shawkey, Jyotsna Shah, Leo Shea, Janet Sperling, and Michael Sweeney for helpful discussion. We thank Dr. Robert B. Allan for technical support and Lorraine Johnson for manuscript review, and we are grateful to Harriet Bishop and Cindy Casey for providing first-hand information about Morgellons disease. 
1. Savely VR, Leitao MM, Stricker RB: The mystery of Morgellons disease: infection or delusion? Am J Clin Dermatol. 2006; 7(1): 1-5.

PubMed Abstract | Publisher Full Text

2. Savely G, Leitao MM: Skin lesions and crawling sensations: disease or delusion? Adv Nurse Pract. 2005; 13(5): 16-17.

PubMed Abstract

3. Middelveen MJ, Stricker RB: Filament formation associated with spirochetal infection: A comparative approach to Morgellons disease. Clin Cosmet Investig Dermatol. 2011; 4: 167-177.

PubMed Abstract | Publisher Full Text | Free Full Text

4. Middelveen MJ, Rassmussen EH, Kahn DG, et al:: Morgellons disease: A chemical and light microscopic study. J Clin Exp Dermatol Res. 2012; 3(1): 140. Publisher Full Text

5. Cheli R, Mortellaro CM: Digital dermatitis in cattle. Proc 8th Int Meet Dis Cattle. Milan, Italy. 1974; 8: 208-213.

Reference Source

6. Blowey RW, Sharp MW: Digital dermatitis in dairy cattle. Vet Rec. 1988; 122(21) 505-508.

PubMed Abstract | Publisher Full Tex

7. Read DH, Walker RL: Papillomatous digital dermatitis (footwarts) in California dairy cattle: clinical and gross pathologic findings. J Vet Diagn Invest. 1998; 10(1): 67-76.

PubMed Abstract | Publisher Full Text

8. Vink WD, Jones G, Johnson WO, et al:: Diagnostic assessment without cut-offs: application of serology for the modeling of bovine digital dermatitis infection. Prev Vet Med. 2009; 92(3): 235-248. PubMed Abstract | Publisher Full Text

9. Borgmann JE, Bailey J, Clark EG: Spirochete-associated bovine digital dermatitis. Can Vet J. 1996; 37(1): 35-37.

PubMed Abstract | Free Full Text

10. Read $\mathrm{DH}$, Walker RL, Castro $\mathrm{AE}$, et al.: An invasive spirochaete associated with interdigital papillomatosis of dairy cattle. Vet Rec. 1992; 130(3): 59-60. PubMed Abstract | Publisher Full Text

11. Grund S, Nattermann H, Horsch F: Electron microscopic detection of spirochetes in dermatitis digitalis of cattle. Zentralb/ Veterinarmed B. 1995; 42(9): 533-542. PubMed Abstract

12. Döpfer D, Koopmans A, Meijer FA, et al:: Histological and bacteriological evaluation of digital dermatitis in cattle, with special reference to spirochaetes and Campylobacter faecalis. Vet Rec. 1997; 140(24): 620-623. PubMed Abstract | Publisher Full Text

13. Demirkan I, Carter SD, Murray RD, et al.: The frequent detection of a treponeme in bovine digital dermatitis by immunochemistry and polymerase chain reaction. Vet Microbiol. 1998; 60(2-4): 285-292. PubMed Abstract | Publisher Full Text

14. Evans NJ, Brown JM, Demirkan I, et al:: Association of unique, isolated treponemes with bovine digital dermatitis lesions. J Clin Microbiol. 2009; 47(3): 689-96. PubMed Abstract | Publisher Full Text | Free Full Text

15. Berry SL, Read DH, Famula TR, et al.: Long-term observations on the dynamics of bovine digital dermatitis lesions on a California dairy after topical treatment with lincomycin $\mathrm{HCl}$. Vet J. 2012; 193(3): 654-8. PubMed Abstract | Publisher Full Text

16. Döpfer D, Anklam K, Mikheil D, et al:: Growth curves and morphology of three Treponema subtypes isolated from digital dermatitis in cattle. Vet J. 2012; 193(3): 685-93.

PubMed Abstract | Publisher Full Text

17. Middelveen MJ, Mayne PJ, Kahn DG, et al: Characterization and evolution of dermal filaments from patients with Morgellons disease. Clin Cosmet Investig
Dermatol. 2013; 6: 1-21 (in press).

PubMed Abstract | Publisher Full Text | Free Full Text

18. Savely VR, Stricker RB: Morgellons disease: analysis of a population with clinically confirmed microscopic subcutaneous fibers of unknown etiology. Clin Cosmet Investig Dermatol. 2010; 3: 67-78.

PubMed Abstract | Free Full Text

19. Savely VR, Stricker RB: Morgellons disease: the mystery unfolds. Expert Rev Dermatol. 2007; 2(5): 585-591.

Publisher Full Text

20. Sapi E, Kaur N, Anyanwu S, et al.: Evaluation of in-vitro antibiotic susceptibility of different morphological forms of Borrelia burgdorferi. Infect Drug Resist. 2011; 4: 97-113.

PubMed Abstract | Publisher Full Text | Free Full Text

21. Mayne PJ: Investigations of Borrelia burgdorferi genotypes in Australia obtained from erythema migrans tissue. Clin Cosmet Investig Dermatol. 2012; 5: 69-78. PubMed Abstract | Publisher Full Text | Free Full Text

22. Bankhead T, Chaconas G: The role of VIsE antigenic variation in the Lyme disease spirochete: persistence through a mechanism that differs from other pathogens. Mol Microbiol. 2007; 65(6): 1547-1558. PubMed Abstract | Publisher Full Text

23. Alessi E, Innocenti M, Ragusa G: Secondary syphilis: Clinical morphology and histopathology. Am J Dermatopathol. 1983; 5(1): 11-17. PubMed Abstract

24. Zoechiling N, Schluepen EM, Soyer HP, et al:: Molecular detection of Treponema pallidum in secondary and tertiary syphilis. Br J Dermatol. 1997; 136(5): 683-686.

PubMed Abstract | Publisher Full Text

25. Pereira TM, Fernandes JC, Viera AP, et al: Tertiary syphilis. Int J Dermatol. 2007; 46(11): 1192-1195.

PubMed Abstract | Publisher Full Text

26. Ekbom KA, Yorston G, Miesch M, et al: The pre-senile delusion of infestation. 1945. Translation: Hist Psychiatry. 2003; 14(54 Pt 2): 229-256. PubMed Abstract | Publisher Full Text

27. Klempner MS, Rogers RA, Noring R: Invasion of human skin fibroblasts by the Lyme disease spirochete Borrelia burgdorferi. J Infect Dis. 1993; 167(5): 1074-1081.

PubMed Abstract | Publisher Full Text

28. Lorenzo CR, Koo J: Pimozide in dermatologic practice: A comprehensive review. Am J Clin Dermatol. 2004; 5(5): 339-349. PubMed Abstract | Publisher Full Text

29. Freudenmann RW, Kölle M, Schönfeld-Lecuona C, et al.: Delusional parasitosis and the matchbox sign revisited: the international perspective. Acta Derm Venereol. 2010; 90(5): 517-519.

PubMed Abstract | Publisher Full Text

30. Hylwa SA, Bury JE, Davis MD, et al:: Delusional infestation, including delusion of patasitosis: Results of histologic examination of skin biopsy and patientprovided skin specimens. Arch Dermatol. 2011; 147(9): 1041-1045. PubMed Abstract | Publisher Full Text

31. Pearson ML, Selby JV, Katz KA, et al.: Clinical, epidemiologic, histopathologic and molecular features of an unexplained dermopathy. PLOS One. 2012; 7(1): e29908.

PubMed Abstract | Publisher Full Text | Free Full Text

32. Stricker RB, Middelveen MJ: Morgellons disease: More questions than answers. Psychosomatics. 2012; 53(5): 504-505. PubMed Abstract | Publisher Full Tex

33. Stricker RB, Johnson L: Lyme disease diagnosis and treatment: Lessons from the AIDS epidemic. Minerva Med. 2010; 101(6): 419-425. PubMed Abstract 


\section{Open Peer Review}

\section{Current Peer Review Status:}

\section{Version 1}

Reviewer Report 03 April 2013

https://doi.org/10.5256/f1000research.304.r760

(c) 2013 English J. This is an open access peer review report distributed under the terms of the Creative Commons Attribution License, which permits unrestricted use, distribution, and reproduction in any medium, provided the original work is properly cited.

\section{John English}

Department of Dermatology, Queen's Medical Centre, Nottingham University Hospitals NHS Trust, Nottingham, UK

It would be nice to know if treating the Borrelia helped the Morgellons disease?

Publisher's note added on 19 Apr 2013: Since the publication of this referee report, a potential conflict of interest has come to light. It appears that just prior to John English completing his report, he and Peter Mayne had been collaborating on another manuscript. Following the publication of the article by Middelveen et al. in F1000Research, Peter Mayne asked Raphael Stricker to become an additional author on this subsequent manuscript, which has since been submitted to F1000Research with Stricker, Mayne and English among the authors. Given this potential conflict of interest, the original referee status has been greyed out on this report but the comments of the reviewer on the article are still accessible.

Competing Interests: No competing interests were disclosed.

I confirm that I have read this submission and believe that I have an appropriate level of expertise to confirm that it is of an acceptable scientific standard.

Reviewer Report 03 April 2013

https://doi.org/10.5256/f1000research.304.r876

(C) 2013 Zelger B. This is an open access peer review report distributed under the terms of the Creative Commons Attribution License, which permits unrestricted use, distribution, and reproduction in any medium, provided the original work is properly cited.

\section{Bernhard Zelger}


Department of Dermatology, Medical University Innsbruck, Innsbruck, Austria

Competing Interests: No competing interests were disclosed.

I confirm that I have read this submission and believe that I have an appropriate level of expertise to confirm that it is of an acceptable scientific standard.

Reviewer Report 03 April 2013

https://doi.org/10.5256/f1000research.304.r867

(C) 2013 Miklossy J. This is an open access peer review report distributed under the terms of the Creative Commons Attribution License, which permits unrestricted use, distribution, and reproduction in any medium, provided the original work is properly cited.

\section{Judith Miklossy}

International Alzheimer Research Center, Alzheimer Prevention Foundation, Martigny-Croix, Switzerland

Pathological characteristics of skin lesions in bovine digital dermatitis and Morgellons disease (MD) show strong similarities. As the role of spirochetal infection in bovine digital dermatitis is established in a comparative analysis, the authors examined the presence of spirochetes in Morgellons disease. They detected Borrelia spirochetes in skin lesions in four randomly selected Morgellons patients who were seroreactive to Borrelia burgdorferi. For the detection of spirochetes various techniques were used, including histochemistry, immunohistochemistry, electron microscopy and polymerase chain reaction. They conclude that spirochetal infection may be a significant factor in the illness and refute claims that the symptoms of patients are delusional and that Morgellons skin lesions are self-inflicted.

This is an important work showing invasion of skin lesions by spirochetes in four Morgellons patients with positive Borrelia serology. The manuscript is well written, and importantly, the authors used various techniques for the detection of spirochetes, which is crucial for such a study. Their results are convincing and only a few and minor comments or changes are suggested, and some propositions for future research. I share the opinion of the authors that these skin lesions are not self-inflicted and they do not correspond to delusional parasitosis. Infection is a significant factor in their pathogenesis.

1. "Representative non-biopsy dermatological specimens" or "representative tissue sample" might be better defined: In the Material and Methods it might be useful for those who would like to perform similar studies to indicate the site of tissue samples, their size and also how they were taken and how they were stored until the analysis.

2. With respect to the detailed histopathological findings of these patients, the authors refer to their previous report (Middelveen et al., 2013) but an inflammatory component of skin lesions cannot be found, probably as skin biopsy was not performed. In future studies, the presence of an inflammatory reaction might be important to analyze as it will support an infectious origin of skin 
lesions.

3. Figures and figure legends

Figure 1: B) With respect to the keratin filaments of bovine digital dermatitis (BDD), it would be useful to insert the method used or refer to a previous publication.

Figure 2: Representative tissue sample - should be more precise. It is not clear whether panel A is a histological section or not? Paraffin or frozen section from skin lesions?

Figure 3: Panels A and B were both taken from the same region of a sample from patient 2. The presence of spirochetes is convincing, however the large "spirochete" in panel B is not comparable to the group of spirochetes seen in the center. I would suggest removing panel B.

Figure 5 : Panel B: Heat shock instantly induces atypical and agglutinated forms of spirochetes, therefore, this panel is not representative to show cultured spirochetes. I would recommend removing this panel. The authors have enough other convincing results. It is not necessary for the study.

C: Probably the spirochete was visualized by immunofluorescence using Borrelia-specific antibody. This should be mentioned.

4. "Although a study from the Centers for Disease Control and Prevention (CDC) found no evidence that pathogens play a role in MD, the search for spirochetal pathogens in that study was confined to Warthin-Starry staining on limited tissue samples and commercial serological testing for Borrelia burgdorferi ${ }^{31}$. Tissue staining in that study was performed on samples from patients who reportedly did not have confirmed clinical evidence of $M D^{32}$, and serological testing was interpreted in accordance with Lyme surveillance criteria that are inappropriate for clinical diagnosis ${ }^{33}$. Thus the findings in the $C D C$ study were influenced by failure to examine the appropriate group of patients and by the clinical insensitivity of surveillance testing for tickborne disease ${ }^{32,33}$. These limitations leave open the possibility that a spirochetal association with MD could have been missed in the CDC study."

The work done by the "Unexplained Dermopathy Study Team" was an important initiative and a well organized and executed work (Pearson et al., 2012), however the population examined in the study was indeed not homogeneous enough, which can make the interpretation of the results difficult. In case definition, to consider the presence of the unusual blue, red or white filaments and if possible, the same stage of skin lesion, would be important. That the authors of this paper examined four Morgellons patients with a positive serology for Borrelia burgdorferi and the case definition of CDC study did not include positive serology for this spirochete may also explain why they did not find Borrelia in their cases. The discrepancy of the results may also be explained if, following the example of bovine digital dermatitis (Döpfer et al., 2012) we anticipate that various types of Treponema species might also be involved in MD. Perhaps the authors may wish to mention that further studies in this direction would be useful. Indeed spirochetes are present not only in ticks but in various other ectoparasites as well. Morphologically diverse populations of spirochetes are abundant and consistently present in termite hindguts (Paster et al., 1996; Ohkuma et al., 1999; Breznak, 2002). Borrelia burgdorferi sensu lato was also detected in mites (Netusil et al., 2005). Spirochetes were detected in lice and also in snails around lakes and fresh waters (Sitnikova et al., 2012). Both humans and cattle are at risk for infection.

\section{5. "Filament formation results from abnormal keratin and collagen expression by epithelial-based}


keratinocytes and fibroblasts"; "Like BDD, MD filaments are produced by epithelial cells and stem from the stratum basale and from the root sheath of hair follicles, thus providing evidence that the filaments are cellular in origin. Furthermore, immunohistochemical and histological staining has demonstrated that these filaments have a collagen as well as a keratin component ${ }^{5,17 . "}$

I would suggest to stay open with respect to the origin of dark and white filaments and just refer to the literature "it was suggested" or "reported" (References) as we have not enough data for a definite conclusion. Helminths show similar properties to those of Morgellons filaments. They show morphological similarities, they are birefringent, they show autofluorescence, and contain keratin- (Shibui et al., 2001; Shinn et al., 1995; Cottee et al., 2006) and collagen-like proteins (e.g. Johnston, 1994; Yang et al., 2012; Kingston and Pettitt, 1990). In schistosomiasis the coexistence of blue and white adult worms is well known. Particularly, the adult female is frequently described as a dark or dark-blue elongated filament (Figure 1 in Kolárová et al., 2010), and cercarial forms (Figure 3 in Savely et al., 2006), might also occur in Morgellons disease. The skin manifestations of cercarial dermatitis or swimmer's itch caused by bird schistosomes are also similar. Compare the skin manifestations in a Morgellons patient with a patient having cercarial dermatitis or swimmer's itch. I would encourage research in this direction. Recent findings show that the parasite may migrate throughout the viscera and the nervous system of mammals, suggesting that the pathogenicity of Trichobilharzia may have been underestimated in the past (Horak et al., 2002). Schistosomiasis is one of the most prevalent parasitic infections worldwide. One should also consider that several helminths can infect together.

6. Melanin pigments are produced by a broad variety of microorganisms, including bacteria, fungi, and helminths (Taborda et al., 2008, Esposito et al., 2012) and a high amount of melanin accumulates in the host around invading worms and cercaria (Babu and Hall, 1974), In this view the Fontana-Masson-stained section from patient 3 from a previous work of the authors (see Figure 3 in Middelveen et al., 2013) demonstrating positive melanin staining "of blue filament sections (arrow)" might be compatible with helminthiasis.

7. Epidermal parasitic skin diseases occur worldwide and a wide range of parasitic infections can involve the skin and subcutaneous tissues, including protozoa, trematodes, cestodes, nematodes and arthropods (Goldsmid and Melrose, 2005). Despite the considerable burden caused by them, they have been widely neglected by the scientific community and health-care providers (Feldmeier \& Heukelbach, 2009). The WHO has included them in a program to remediate this situation. Following the various findings available with respect to 'Morgellons disease' it seems that various parasites should be considered and investigated in each case. Efficient treatments would be available. In order to contribute to this goal and to avoid controversies, open discussions will be necessary. Further research is essential.

\section{References}

1. Cogswell AA, Kommer VP, Williams DL: Transcriptional analysis of a unique set of genes involved in Schistosoma mansoni female reproductive biology.Plos One.2012; 6 (11). PubMed Abstract I Free Full Text | Publisher Full Text

2. Babu JP, Hall JE: Histochemical Staining of Melanin Formed in a Mayfly in Response to Helminth Infection.J. Intervertebrate Pathol.1974. 123-124 Reference Source

3. Breznak JA: Phylogenetic diversity and physiology of termite gut spirochetes.Integr Comp Biol. 
2002; 42 (2): 313-318 PubMed Abstract | Publisher Full Text

4. Cottee PA, Nisbet AJ, Abs El-Osta YG, Webster TL, et al.: Construction of gender-enriched cDNA archives for adult Oesophagostomum dentatum by suppressive-subtractive hybridization and a microarray analysis of expressed sequence tags.Parasitology. 2006; 132 (Part 5): 691-708 PubMed Abstract | Publisher Full Text

5. Döpfer D, Anklam K, Mikheil D, et al.: Growth curves and morphology of three Treponema subtypes isolated from digital dermatitis in cattle.Vet J.2012; 193 (3): 685-93 PubMed Abstract | Publisher Full Text

6. Esposito R, D'Aniello S, Squarzoni P, Pezzotti MR, et al.: New Insights into the Evolution of Metazoan Tyrosinase Gene Family. Plos One.2012; 7 (4). PubMed Abstract | Free Full Text | Publisher Full Text

7. Feldmeier $\mathrm{H}$, Heukelback J: Epidermal parasitic skin diseases: a neglected category of povertyassociated plagues.Bulletin of the World Health Organization. 2009; 87 (2): 152-9 PubMed Abstract | Free Full Text | Publisher Full Text

8. Goldsmid JM, Melrose W: Parasitic infections of the skin. Primer of Topical Medicine. Reference Source

9. Horák P, Kolárová L: Biology of the schistosome genus Trichobilharzia.Adv Parasitol.2002; 52: 155-233 PubMed Abstract

10. Johnstone IL: The cuticle of the nematode Caenorhabditis elegans: a complex collagen structure.Bioessays.1994; 16 (3): 171-8 PubMed Abstract

11. Kingston IB, Pettitt J: Structure and expression of Ascaris suum collagen genes: a comparison with Caenorhabditis elegans.Acta Trop.1990; 47 (5-6): 280-7 PubMed Abstract

12. Kolárová L, Horák P, Skírnisson K: Methodical approaches in the identification of areas with a potential risk of infection by bird schistosomes causing cercarial dermatitis.J. Helminthol. 2010; 84 (3): 327-35 PubMed Abstract | Publisher Full Text

13. Middelveen MJ, Kahn DG, Stricker RB: Characterization and evolution of dermal filaments from patients with Morgellons disease.Clinical, Cosmetic and Investigational Dermatology.2013; 6: 1-21 PubMed Abstract | Free Full Text | Publisher Full Text

14. Netusil J, Zákovská A, Horváth R, Dendis M, et al.: Presence of Borrelia burgdorferi sensu lato in mites parasitizing small rodents.Vector Borne Zoonotic Dis.2005; 5: 227-232 PubMed Abstract | Publisher Full Text

15. Ohkuma M, Lida T, Kudo T: Phylogenetic relationships of symbiotic spirochetes in the gut of diverse termites.FEMS Microbiol Lett.1999; 181: 123-129 PubMed Abstract | Publisher Full Text 16. Paster BJ, Dewhirst FE, Cooke SM, Fussing V, et al.: Phylogeny of not-yet-cultured spirochetes from termite guts.Appl Environ Microbiol.1996; 62: 347-352 PubMed Abstract | Free Full Text | Reference Source

17. Pearson ML, Selby JV, Katz KA, Cantrell V, et al.: Clinical, epidemiologic, histopathologic and molecular features of an unexplained dermopathy.PLoS One.2012; 7: e29908 PubMed Abstract I Publisher Full Text

18. Savely VR, Leitao MM, Stricker RB: The mystery of Morgellons: infection or delusion?. Am J Clin Dermatol.2006; 7: 1-5 PubMed Abstract | Reference Source

19. Shibui A, Takamoto M, Shi Y, Komiyama A, et al.: Cloning and characterization of a novel gene encoding keratin-like protein from nematode Nippostrongylus brasiliensis.Biochim Biophys Acta. 2001; 1522: 59-61 PubMed Abstract | Publisher Full Text

20. Shinn AP, Gibson DI, Sommerville C: A study of the composition of the sclerites of Gyrodactylus Nordmann, 1832 (Monogenea) using X-ray elemental analysis.Int J Parasitol.1995; 25: 797-805 PubMed Abstract | Publisher Full Text

21. Sitnikova T, Michel E, Tulupova Y, Khanaev I, et al.: Spirochetes in gastropods from Lake Baikal 
and North American freshwaters: new multi-family, multi-habitat host records.Symbiosis.2012; 56: 103-110 Publisher Full Text

22. Taborda CP, da Silva MB, Nosanchuk JD, Travassos LR: Melanin as a virulence factor of Paracoccidioides brasiliensis and other dimorphic pathogenic fungi: a minireview.Mycopathologia. 2008; 165: 331-339 PubMed Abstract | Free Full Text

23. Yang $Y$, Jin $Y$, Liu $P$, Shi $Y$, et al.: RNAi silencing of type $V$ collagen in Schistosoma japonicum affects parasite morphology, spawning, and hatching.Parasitol Res.2012; 111: 1251-1257 PubMed Abstract | Publisher Full Text

Competing Interests: No competing interests were disclosed.

\section{I confirm that I have read this submission and believe that I have an appropriate level of expertise to confirm that it is of an acceptable scientific standard.}

\section{Comments on this article}

\section{Version 1}

Author Response 11 Mar 2014

Raphael Stricker, University of New Haven, West Haven, CT, USA

Reply from Raphael B. Stricker, MD, and Marianne J. Middelveen, Mdes:

We would like to address the "Objection" to our study of Morgellons disease that was posted by Steven Salzberg on the F1000Research website. Salzberg has a PhD in computer science and appointments in genetic medicine, biostatistics and computer science at Johns Hopkins University. Based on his comments he appears to have limited knowledge of the recent medical literature about Morgellons disease and limited understanding of the sophisticated scientific methods used in our study to demonstrate the presence of the Lyme disease spirochete, Borrelia burgdorferi, in patients with Morgellons disease.

Salzberg starts by praising the deeply flawed CDC and Mayo Clinic Morgellons studies, which were extensively criticized in the Discussion section of our article and elsewhere ${ }^{1}$. For example, the retrospective CDC study by Pearson et al. failed to identify patients with dermopathy, used insensitive serological testing and limited tissue staining in an attempt to detect spirochetal infection, and failed to include specific culture or PCR testing for $B$. burgdorferi in any of their patients $^{1,2}$. The retrospective Mayo Clinic studies by Hylwa et al. noted that patients with "delusional" dermopathy had a high rate of psychiatric symptoms and no evidence of "infestation". However comparable rates of psychiatric symptoms occur in patients with other chronic nondelusional medical conditions, suggesting that the symptoms are the result rather than the cause of the condition, and specific testing for spirochetal infection was not performed ${ }^{1,3}$. Thus these flawed studies failed to look for the right infection in the right patients using the right techniques.

Salzberg goes on to say that our article is "little more than 4 PCR results", ignoring the detailed culture, immunohistochemical and electron microscopical evidence presented in this study and in 
our previous investigations of Morgellons disease $\mathrm{e}^{4,5}$. He then misinterprets the PCR data, somehow confusing it with the study of Australian Morgellons patients who had spirochetes in their lesions that were shown to be Borrelia garinii by PCR in one case ${ }^{6}$. In fact, the Australian study confirms that $B$. burgdorferi strains are associated with Morgellons disease ${ }^{6}$. In the Discussion section of our article we made it clear that we had not subtyped the $B$. burgdorferi PCR sequences because we were only using PCR to confirm the extensive and convincing scientific findings in the rest of the study that point to $B$. burgdorferi involvement in Morgellons disease. Thus the weight of scientific evidence confirms an association between B. burgdorferi and Morgellons disease.

We think that it is irresponsible and antiscientific for Salzberg to characterize our careful, detailed, multifaceted and peer-reviewed article as "pseudoscience", and his "Objection" has no merit. In contrast, the link between Morgellons disease and B. burgdorferi infection merits further scientific investigation.

References:

1. Stricker RB, Middelveen MJ. Morgellons disease: More questions than answers Psychosomatics. 2012;53(5):504-5.

2. Pearson ML, Selby JV, Katz KA, Cantrell V, et al, for the Unexplained Dermopathy Study Team. Clinical, epidemiologic, histopathologic, and molecular features of an unexplained dermopathy. PLoS One 2012;7(1):e29908.

3. Hylwa SA, Foster AA, Bury JE, Davis MD, et al. Delusional infestation is typically comorbid with other psychiatric diagnoses: review of 54 patients receiving psychiatric evaluation at Mayo Clinic. Psychosomatics 2012; 53(3):258-265.

4. Middelveen MJ, Stricker RB: Filament formation associated with spirochetal infection: a comparative approach to Morgellons disease. Clin Cosmet Investig Dermatol 2011; 4:167-177.

5. Middelveen MJ, Rasmussen EH, Kahn DG, Stricker RB: Morgellons disease: a chemical and light microscopic study.J Clin Exp Dermatol Res 2012; 3:140.

6. Mayne P, English JS, Kilbane EJ et al. (2013) Morgellons: a novel dermatological perspective as the multisystem infective disease borreliosis [v1; ref status: approved 1, approved with reservations 1, not approved 2, http://f1000r.es/116] F1000Research 2013, 2:118 (doi: 10.12688/f1000research.2118.v1)

Competing Interests: None

\section{A Objection}

Reader Comment ( ) 13 Oct 2013

Steven Salzberg, McKusick-Nathans Institute of Genetic Medicine, Johns Hopkins University, USA 
This article contains very serious scientific flaws and should never have been published. The disorder called 'Morgellons Disease' (MD) was only recently described based on patients' own selfdiagnoses, and it has been examined extensively and found to have no physical basis. The CDC reported (http://www.cdc.gov/unexplaineddermopathy/) that the fibers on the skin of patients were clothing fibers. They also found that "Upon thorough analysis, most sores appeared to result from chronic scratching and picking, without an underlying cause". The CDC and a recent review from the Mayo Clinic (http://www.ncbi.nlm.nih.gov/pubmed/22264448) concluded that MD is a form of delusional parasitosis, and that patients complaining of Morgellons likely need psychiatric treatment.

The authors of this study deny the published evidence, and instead are trying to claim that MD is caused by a form of chronic Lyme disease. Chronic infection with B. burgdorferi, like MD, has been shown in multiple studies to have no scientific basis.

The evidence presented in this article is little more than 4 PCR results, of which one showed no evidence of $B$. burgdorferi, one was weakly positive, and two were positive. The sequences amplified, which are shown in the Opinion article (http://f1000research.com/articles/2-118/v1) but not here, supposedly have BLAST alignments to another Borrelia species, B. garinii, but the alignments are so weak that they could easily represent other common skin bacteria. The authors also fail to explain why the sequences don't match $B$. burgdorferi, the primary Lyme disease spirochete. Thus even their positive samples don't match the right species.

The claims and assertions made in this article are not only flawed, but they represent dangerous pseudoscience. Patients could easily be misled into taking long-term antibiotics for a condition that instead requires psychiatric care or other treatment.

Competing Interests: None

The benefits of publishing with F1000Research:

- Your article is published within days, with no editorial bias

- You can publish traditional articles, null/negative results, case reports, data notes and more

- The peer review process is transparent and collaborative

- Your article is indexed in PubMed after passing peer review

- Dedicated customer support at every stage

For pre-submission enquiries, contact research@f1000.com 